\title{
Internet Exchange and Forms of Trust
}

\author{
Denise Anthony \\ Dartmouth College, USA \\ James A. Kitts \\ Columbia University, USA \\ Christopher Masone \\ Google, USA \\ Sean W. Smith \\ Dartmouth College, USA
}

\section{ABSTRACT}

All economic exchange entails some uncertainty, but uncertainty is exacerbated in periods of social change that disrupt conventional patterns and modes of exchange. The increasing reliance on the Internet as a medium for exchange has greatly increased uncertainty, raising particular problems of trust between parties. In this study, we examine how information that may reduce uncertainty affects individuals' trust in online exchange. Within an experimental marketplace, we present subjects with a series of simulated vendors along with ratings of the vendors' transaction security. Specifically, we manipulate the source of reputation information (interpersonal vs. institutional sources) and the content of information (rating of reliability vs. capability for engaging in secure transactions) for those vendors, then assess subjects' tendency to trust in vendors. We find that although subjects are responsive to the item price and vendor rating, and subjects are more likely to trust vendors when given reputation information from institutional sources, they do not differentiate capability from reliability information in evaluating vendors in this context.

\section{INTRODUCTION}

A recent radio news story described a now common $21^{\text {st }}$ century event: the closing of a family-owned retailer after 70 years of selling sheet music in New York City (Adler, 2009). Former patrons reminisced that the shop was a well-known, reliable source not only of musical scores for every imaginable instrument and voice, but also of advice regarding how various editions of the same score were suited to the needs of each buyer. While some noted that online sources now provide access to many of the same scores, they also suggested that customers would no longer receive the personalized service that they had previously enjoyed. Leading conductors as well as novices had relied on the shop to reduce their uncertainty surrounding each purchase.

Virtually all economic exchange entails some uncertainty; there is often asymmetry of information between buyer and seller and there is no guarantee that a partner will behave as promised for exchanges that are asynchronous. Periods of social change can exacerbate uncertainty by introducing new exchange partners and situations. For example, in the industrial revolution, major demographic shifts from urban and international migration increased contact among strangers and across cultures, complicating exchange. Industrialization further introduced new forms of organization (e.g., bureaucratic factories) and new types of exchange (e.g., wage labor) (Perrow, 2002). Increased uncertainty regarding potential partners and exchange situations meant that social actors often could no longer rely on interpersonal trust, based in established relationships with known others. Instead, new institutions were created to reduce uncertainty and facilitate the trust required for exchange (Shapiro, 1987; Zucker, 1986). 
Increasing reliance on the Internet as a medium for exchange has greatly increased uncertainty in transactions by inviting contact between unknown trading partners in new and foreign exchange situations. Uncertainty is even greater on the Internet because potential exchange partners may be anonymous or at least have no fixed identity (Friedman \& Resnick, 2001). Given such high levels of uncertainty and the unique opportunity to observe exchange in a new environment, it is not surprising that much research across many disciplines has been devoted to the question of trust in online exchange (Baye, 2002; Camp, 2000; Cheshire \& Cook, 2004; Falcone et al, 2001; Friedman \& Resnick, 2001; Kollock, 1999; Lunn \& Suman, 2002).

Uncertainty may be mitigated by information received from third parties, whether by peers or institutional actors. This project investigates how different sources and types of information about vendors affect propensity to trust in and purchase from online vendors. In the next section, we describe differences between interpersonal and institutional trust. We then describe some theoretical and empirical studies of trust mechanisms used in online exchange. Next we describe a laboratory experiment that examines how different types of information from interpersonal or institutional sources affect exchange in an online marketplace. Finally, we discuss the implications and limitations of our study, including questions remaining for future research.

\section{BACKGROUND}

Social conditions that increase uncertainty are often viewed as problems of trust. When actors depend on each other for valued outcomes, they are vulnerable to others' choices; in these conditions, any uncertainty about others' motives and future actions raises a fundamental dilemma of trust (Coleman, 1990; Hardin, 2002; Heimer, 2001; Luhman, 1979; Molm et al 2000). Trust is generally relevant for situations in which "participants are uncertain and vulnerable - they lack information about what others can and will do, but they also have a stake because they cannot achieve their objectives without the cooperation of others” (Heimer, 2001, p.42). According to Bacharach and Gambetta (2001), uncertainty is the primary problem of trust.

\section{Uncertainty and Forms of Trust}

We specifically define trust as an actor's positive expectations of an exchange partner's conduct, such that the actor is willing to take some action that makes her vulnerable to her partner's behavior (Barber, 1983; Coleman, 1990; Garfinkle, 1967; Hardin, 2002; Luhman, 1979; Schutz, 1970). Russell Hardin specifies trust as a three-part relation, such that A trusts B to do X, though we rarely talk about trust in such complete terms (Hardin, 2002, p.5). For example, if Alice trusts Bob to repay her, she loans him \$10. Alice is now vulnerable because she risks losing her ten dollars, and possibly more if Bob's failure to repay will jeopardize their relationship. However, Alice may feel more certain about Bob repaying the loan if she has information that Bob is reliable.

Although information is a straightforward remedy to uncertainty, gathering and evaluating information is costly and difficult (Simon, 1955; Kollock \& O’Brien, 1992). Further, information asymmetries in exchange result because "minds are private"; that is, intentions are not known (Rasmusen, 1984; Kreps, 1990). Thus, social conditions can influence the availability and accessibility of information about potential exchange partners. Actors embedded in a social network may have information about a partner's history either from direct experience or from others in the network (Granovetter, 1985; Greif, 1989, 1993). In the example of interpersonal trust above, Alice may trust Bob, and thus be willing to lend him money, because he has honored her trust in the past or she may have information from others who vouch for Bob's reliability. Information about a partner's past reliability increases the likelihood of successful exchange (Burt \& Knez, 1996; Dawes, 1980; Raub \& Weesie, 1990). Somewhat differently, social relationships also can assure reliability not by providing information about a partner's past, but 
rather through providing incentives or constraints that ensure his good conduct in the future. Axelrod (1984) described how the "shadow of the future" in ongoing interaction can dissuade opportunistic behavior because mistreating a partner will have negative consequences for oneself. According to Hardin (2002, p.19), "shared interests make for the reliability of the trusted."

Uncertainty in exchange can also stem from lack of information about an exchange partner's competence to deliver on promises (Barber, 1983, pp.9-15; Heimer, 2001, p.44) or about the quality of the commodities traded (Akerlof, 1970; Greif, 1993; Kollock, 1994). That is, a trustee may fail to honor trust either because she is unwilling to do so or because she is unable, a distinct problem of capability or competence (Coleman, 1990 p. 96). Perceptions also matter: A party may be unwilling to trust another actor who she believes is incapable of honoring trust, even when such concerns are unjustified. When there is uncertainty about either competence or quality in exchange, actors will seek committed relationships (DiMaggio \& Louch, 1998; Greif, 1989, 1993; Kollock, 1994). That is, they seek out social ties in order to use the reliability that they expect from their stable relationships to compensate for lack of information regarding capabilities. For example, high reliability through social relationships compensates for deficits in creditworthiness in microcredit borrowing groups (Anthony, 2005; Anthony \& Horne, 2003) and in credit card markets (Guseva \& Rona-Tas, 2001; see also Cook et al, 2004). Research on interpersonal trust typically avoids these complications by focusing on the problem of reliability, using ensured capability as an implicit scope condition (see Hardin, 2002; Gambetta, 1988; Luhman, 1988; Snijders, 1996). As a result, such theories of interpersonal trust only apply where a trustee's capability is not in question. Although researchers acknowledge that capability varies in empirical situations of interpersonal trust (e.g. Hardin, 2002: p. 8), they typically focus attention on motivational issues and leave questions of competence aside. The interplay of reliability and capability in interpersonal trust thus remains largely unexplored.

In the absence of social relationships, third party institutions can provide information regarding actors' reliability or capability to facilitate trusted exchange ${ }^{1}$ (Heimer, 2001; Shapiro, 1987; Yamagishi, 1995; Zucker, 1986). As noted above, increased uncertainty regarding trading partners and transactions during the late $19^{\text {th }}$ and early $20^{\text {th }}$ centuries led to the creation of new institutions to provide information to unknown exchange partners or in new types of transactions. New third-party institutions for the licensure and accreditation of occupations and organizations, for example, became a source of information about actors' capabilities. Other institutions began to assure reliability, either through information about past behavior (e.g., Better Business Bureau) or by providing incentives to deliver on promises regardless of exchange partner identities (e.g., laws and regulatory bodies). Consistent with economic sociology claims regarding the role of institutions in markets, it is by "establishing particular legal, social and informational conditions, [that] institutions make the production, distribution, and exchange of commodities possible (Carruthers et al, 2001, p.94, italics added). Yamagishi and Yamagishi (1994) refer to these third party institutions as assurance rather than trust mechanisms to distinguish the sources of information and enforcement in institutional trust from those for interpersonal trust. For institutional trust, information comes from an organization, not peers, and may be regarding the reliability of an exchange partner, the capability, or both. 


\begin{tabular}{|c|l|l|}
\hline \multirow{2}{*}{$\begin{array}{l}\text { Content of } \\
\text { Information }\end{array}$} & \multicolumn{2}{|c|}{ Source of Information } \\
\cline { 2 - 3 } RELIABILITY & $\begin{array}{l}\text { INTERPERSONAL } \\
\begin{array}{l}\text { Direct experience } \\
\text { Reputation: history of past } \\
\text { reliable behavior } \\
\text { Assurance mechanisms: norms, } \\
\text { threat of peer sanctions }\end{array}\end{array}$ & $\begin{array}{l}\text { INSTITUTIONAL } \\
\text { Assurance mechanisms: contracts, } \\
\text { laws, criminal and civil penalties }\end{array}$ \\
\hline CAPABILITY & $\begin{array}{l}\text { Observation: evidence of ability } \\
\text { Reputation: performance history }\end{array}$ & $\begin{array}{l}\text { Licensure and accreditation bodies } \\
\text { Certification }\end{array}$ \\
\hline
\end{tabular}

Figure 1. Dimensions of Reputation Information for Reducing Uncertainty in Trust Dilemmas

We can distinguish interpersonal from institutional forms of trust by considering differences along two dimensions of uncertainty-reducing information: (1) the content of the information about the trustee, and (2) the source of that information (see Figure 1). The content of evaluative information about the trustee may be either the trustee's reliability, that is, the likelihood that the trustee will do the trusted action based on assessments of past behavior or future incentives and constraints, or the trustee's capability, that is, the likelihood that the trustee can do the trusted action. There are also two general types of sources for evaluative information, interpersonal sources (whether direct ties to peers or indirect diffusion of information, such as reputations or gossip) or institutional sources (such as licensure and accreditation bodies).

Information from interpersonal sources, including both direct experience and reputation information from peers, may ameliorate uncertainty about the trustee's reliability. Interpersonal sources may also supply evaluative information on the trustee's capabilities, such as through a reputation for competence or resourcefulness. Information from institutional third parties may ameliorate uncertainties about either reliability of the trustee (either by an official record of past dealings, such as a criminal record, or legal constraints on future actions) or may provide a formal assessment of capabilities (such as licensure and accreditation). In this study, we present a set of individuals with a problem of uncertainty in exchange, and examine how these two different kinds of information from these two different sources may affect trust in online exchange.

\section{Trust and Internet Exchange}

Recent years have seen the rapid proliferation of online reputation and recommender systems, which rely on individuals sharing information about their experiences with individual sellers (Cheshire \& Cook, 2004; Resnick et al, 2000). Such systems provide low-cost reliability information from peers consistent with interpersonal trust (Kollock, 1999), despite the vast size of the network and the limited availability of personally identifying information online. Some argue that reputation systems could be the basis for all trusted Internet-based communication and exchange (e.g., Camp et al, 2002). In the large, open transaction system of the Internet, however, interpersonal trust is likely to become less effective over time, as suggested by Güth and Kliemt (2004; see also Yamagishi \& Matsuda, 2003) because reputation systems work best in closed networks (Cheshire \& Cook, 2004) and online reputations are vulnerable to 
strategic abuse (David \& Pinch, 2005). However, new institutionalized sources of information that can overcome the limitations of interpersonal trust have yet to be established online. ${ }^{2}$

\section{A SOCIAL EXPERIMENT FOR TRUST IN INTERNET EXCHANGE}

To investigate how interpersonal and institutional trust mechanisms influence exchange, we developed a laboratory version of an online marketplace, in which consumers encounter simulated vendors. Each of 73 subjects took part in a series of purchase decisions from different vendors. More specifically, subjects visited a simulated website called "WhatsThePrice.com" which gave them an opportunity to either accept or decline a purchase from each of 12 vendors. Subjects earned points for making purchases from 'legitimate' vendors, but not for exchanges with vendors that were 'not legitimate' (i.e., where the vendor would not successfully complete the exchange, regardless of reason such as incompetence or fraud). Subjects began each round with a pool of 5 points and decided whether to make a purchase or not. If subjects chose to make a purchase and the vendor was legitimate, they tripled their 5 points to 15; if they chose to make a purchase but the vendor was not legitimate, they lost their 5 points; if they chose not to make a purchase they kept the 5 points.

The experiment simulates the truster's move in a standard trust game when the truster has the opportunity to engage in the exchange (trust the trustee) or not. Subjects were informed that they were helping to evaluate the characteristics and usability of a new website for consumers seeking information about online vendors. Subjects were not deceived in this experiment, and were completely aware that they were not making actual purchases from online vendors on a real web page.

For each vendor, subjects received information about the commodity for sale: the seller's asking price and a range of prices that contained the true fair market value of the item. For example, a subject may receive an invitation to buy an item for $\$ 9$, along with the information that the item is truly worth anywhere from $\$ 6$ to $\$ 15$. The subjects also received a rating of the vendor; the source and the basis of this rating were manipulated in the experiment. Some of the items were cheap (with asking price from $\$ 8$ to \$25) and others were expensive (with asking price from $\$ 85$ to $\$ 110$ ). Each subject was exposed to 6 cheap items and 6 expensive items (within-subject exposure) and the fair market value range was held constant across vendors as a fixed proportion of the asking price.

Subjects were shown a rating of each vendor on a 1-5 scale (though all subjects saw ratings only in the range of 3-5). The scale was described as similar to a grading scale of A through $\mathrm{F}$, in which $5=\mathrm{A}$ or the highest rating possible, and $1=\mathrm{F}$ or the lowest rating possible. The information content that was the basis for the rating (reliability versus capability) and the source of the rating (peers or institutions) varied across subjects for a 2 X 2 between-subjects design. Figure 2 shows the four types of providers of the vendor ratings by the two dimensions of reputation information for trusted exchange. Subjects were informed of the different providers of vendor ratings, but each received ratings from only one provider (between subject exposure).

Consumer feedback and rating systems (column one in Figure 2) provide information similar to word-ofmouth information in offline settings, that is, similar to social ties for interpersonal trust. Feedback systems provide information on a vendor's reliability based on the experiences of customers. Consumer rating systems offer customers the ability to evaluate vendors along various dimensions; here we define the rating as based on evaluations of security. Similarly, the two types of institutional sources (column two in Figure 2) are independent third-party organizations that evaluate vendors on either their history of secure transactions (reliability) or their technical capability for conducting secure transactions. 


\begin{tabular}{|c|c|c|}
\hline \multirow{2}{*}{$\begin{array}{l}\text { Content of } \\
\text { Information }\end{array}$} & \multicolumn{2}{|c|}{ Source of Information } \\
\hline & INTERPERSONAL Rating & INSTITUTIONAL Rating \\
\hline $\begin{array}{r}\text { RELIABILITY } \\
\text { Vendor has history } \\
\text { of conducting secure } \\
\text { online transactions }\end{array}$ & $\begin{array}{l}\text { Customers' feedback about } \\
\text { their experiences of the } \\
\text { security of transactions } \\
\text { with online vendors } \\
\sim \text { www.BuyReliable.org } \sim \\
\text { Reliable information from } \\
\text { consumers like you! }\end{array}$ & 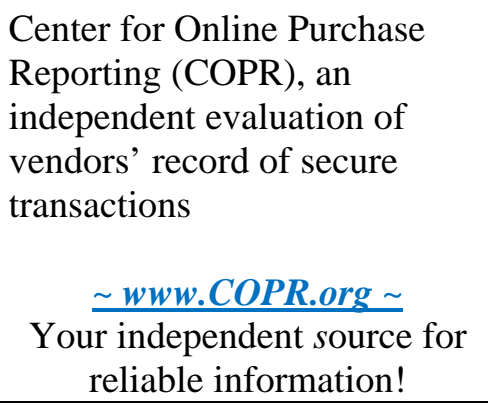 \\
\hline $\begin{array}{r}\text { CAPABILITY } \\
\text { Vender has } \\
\text { technical capacity to } \\
\text { conduct secure } \\
\text { online transactions }\end{array}$ & $\begin{array}{l}\text { Customer assessments and } \\
\text { discussion of the security of } \\
\text { online vendors } \\
\begin{array}{c}\sim w w w . B u y \text { Secure.org } ~ \\
\text { Use the power of consumer } \\
\text { feedback for online } \\
\text { security! }\end{array}\end{array}$ & 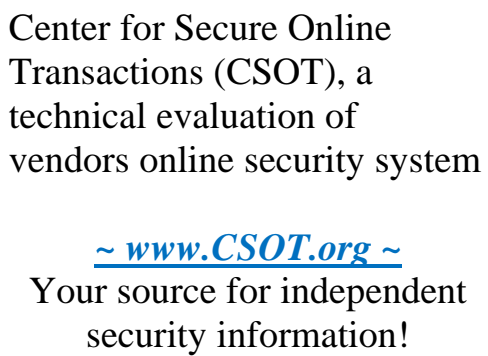 \\
\hline
\end{tabular}

Figure 2. Vendor rating providers by information dimensions for WhatsThePrice.com experimental online marketplace

In response to a recruitment advertisement, undergraduate students visited a website at which they completed an Informed Consent form and a brief survey regarding their experience in Internet commerce, risk preferences, generalized trust, and demographic characteristics. Upon completing the survey, subjects received a numeric identifier (ID). Subjects brought the ID to an experiment session in a public computer lab, where they received instructions and each subject completed the experiment at a private computer terminal. Subjects did not communicate with one another during the experiment and could not see other subjects' choices or outcomes.

At the end of the session, subjects completed a brief post-survey and were debriefed. The numeric ID was used to anonymously link the survey responses to the experiment results. Participation in the study required approximately 30-45 minutes of subjects' time, including both surveys and the experiment session. For this time, subjects were paid at least $\$ 5$ and up to $\$ 20$, depending on their outcomes in the experiment. The actual legitimacy of vendors was random and uncorrelated with ratings, regardless of the information content or source. Subjects did not learn the results of individual purchase decisions and did not receive even overall feedback on their performance until the end of the game, so no learning about vendor characteristics or other feedback on subject strategies was possible. We found no evidence of order effects.

\section{Experiment Results}

A total of 73 subjects participated in the experiment, with 12 rounds per session, for a total of $n=876$ observations. Two-thirds of the subjects were women $(n=50)$ and $60 \%$ were white $(n=44)$. Analyses treat information content (reliability, capability), information source (interpersonal, institutional), price (cheap, 
expensive), and rating (low, medium, high) as categorical independent variables. Specifically, we model the odds of accepting purchases using logistic regression, with Huber-White robust standard errors for repeated observations by subject.

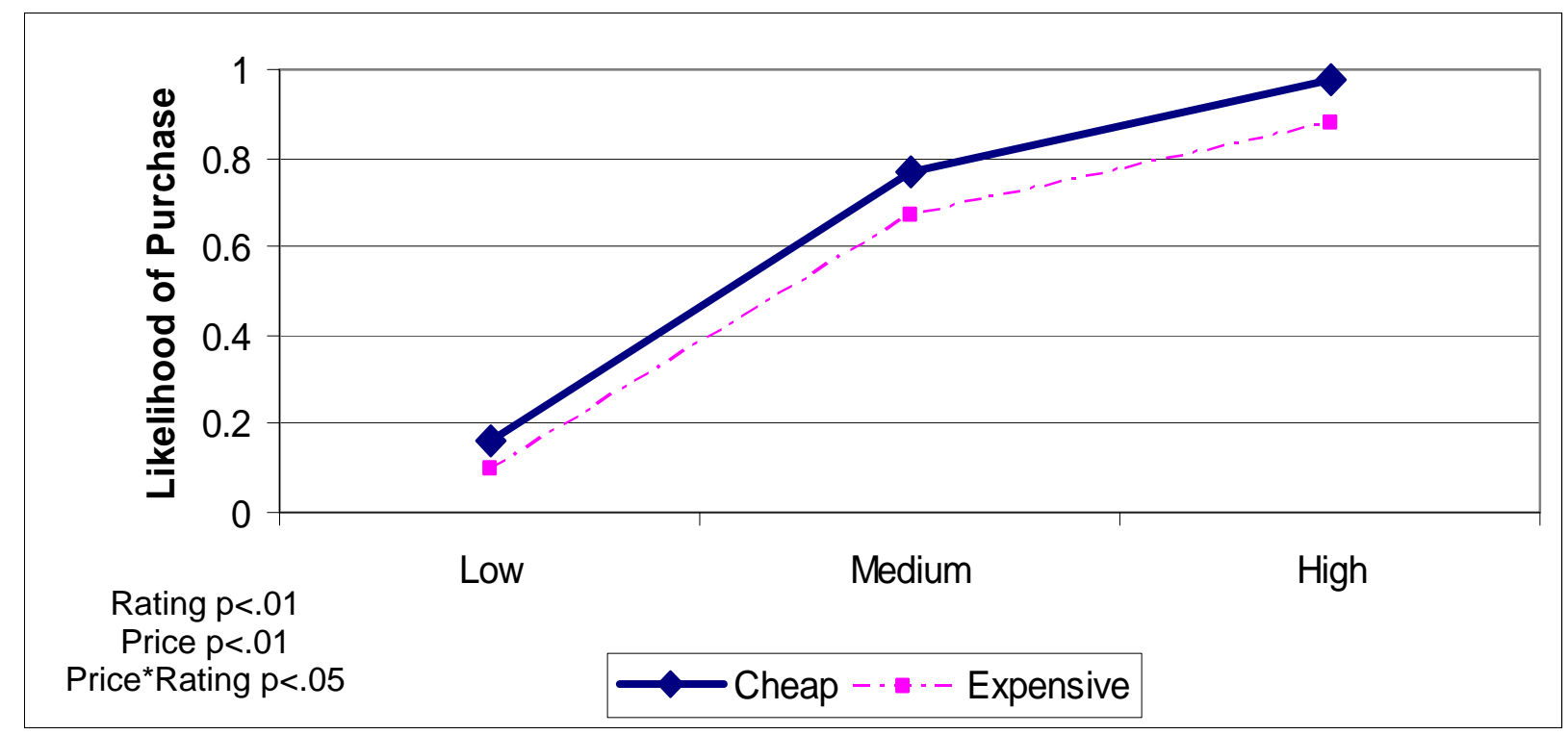

Figure 3. Likelihood of making purchase by price of goods and rating of vendor, $n=876$

Figure 3 presents the predicted probabilities from models including only dummy variables for price and the three vendor rating levels. We see that few subjects were willing to make a purchase from vendors with low ratings, while the majority of subjects purchased at medium ratings, and almost all purchased from vendors with high ratings. The price of the goods also influenced subjects' willingness to purchase from online vendors; they were significantly more likely to purchase cheaper items overall (main effect of price is significant). The interaction of price and rating is statistically significant, although the effect of price is qualitatively similar for all vendor ratings, and vice versa.

The fact that subjects responded strongly and positively to vendor ratings is unsurprising. However, the mild negative effect of item price is intriguing, as subjects were aware that their performance in the experiment (and thus their rewards for participating) was not related to the money they spent in purchases; they were asked to judge only whether or not vendors were 'legitimate.' Apparently, they were less likely to judge a vendor as legitimate if the price was greater. It may be that they scrutinized highcost goods more carefully, even though the same amount of information was provided for all vendors, and subjects knew their outcomes were not related to price. Given that the fair value range was computed in proportion to the asking price, and thus the fair value range was greater in absolute terms for the more expensive items, it is possible that subjects may have perceived a higher uncertainty in the exchanges for expensive items. This uncertainty may have led them to judge the vendor as less legitimate, but further work is needed to investigate this conjecture. 


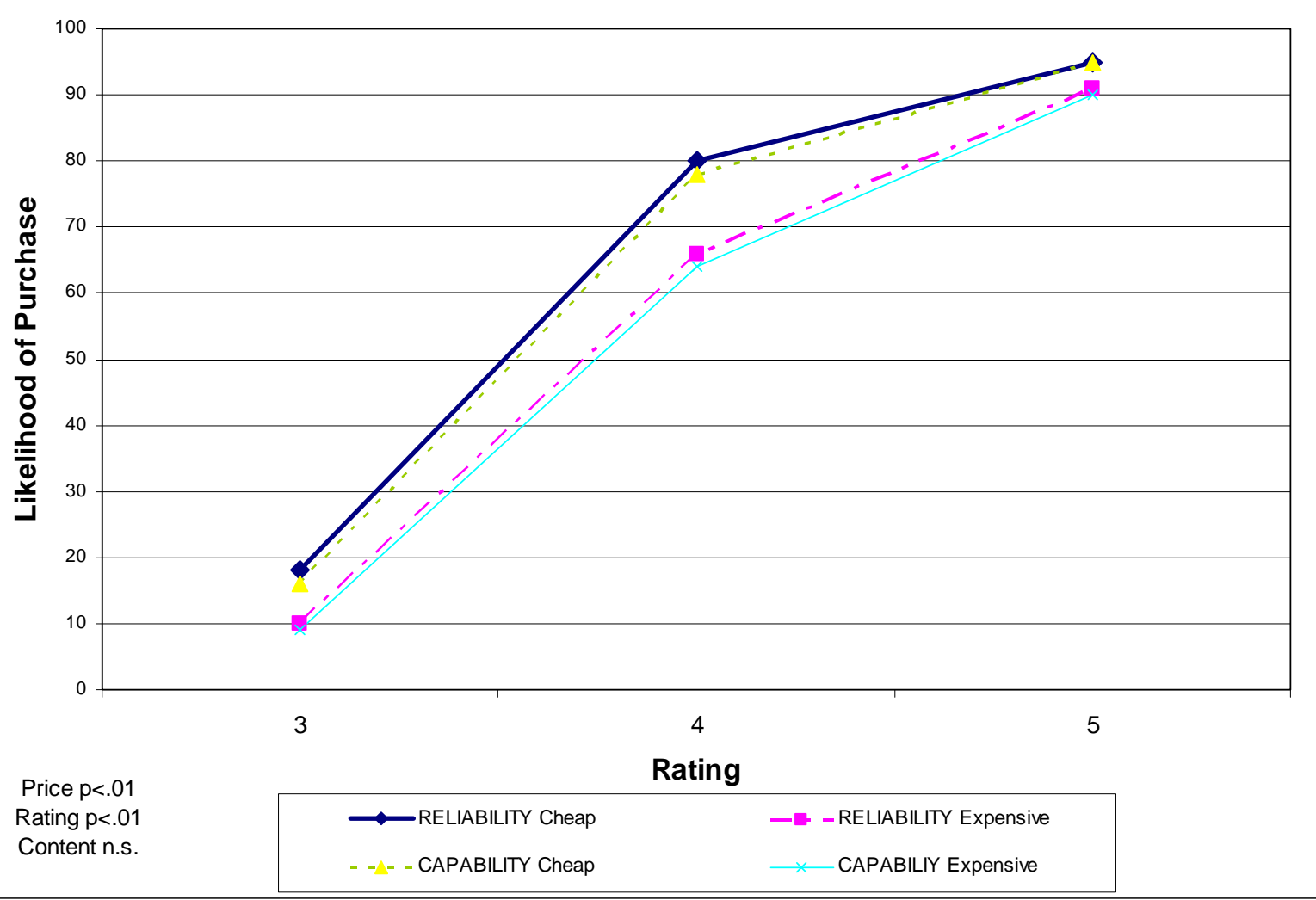

Figure 4. Likelihood of making an online purchase by price of good, vendor rating and content of information provided about the vendor, $n=876$

Figure 4 shows the main experimental results for the effect of information content (reliability versus capability) on likelihood of making a purchase. While price and rating are still significant, there is no significant difference in likelihood of purchase between those who received reliability information versus those who received capability information. The two-way and three-way interactions between content, rating and price are also not significant (data not shown).

Figure 5 shows the results for the effect of information source (institutional vs. interpersonal ratings) on likelihood of purchase. The effects for price and rating are similar to those shown in Figure 3. Subjects were generally more likely to purchase when vendors were rated by an institutional rather than interpersonal source (consumers), but the main effect of source is not statistically significant. The twoway interaction between source and price is not significant but the interaction between source and rating is significant $(\mathrm{p}<.05)$. It appears that subjects felt most uncertain about, and therefore showed more variation in purchasing for vendors with a rating of 4 . In contrast, the subjective strength of a 5 rating or the weakness of a 3 rating appear so salient that subjects do not discriminate very much by either information source or content in those conditions. If we look at the effect of source on willingness to purchase from vendors with a rating of 4 only, we find that source is significant $(p<.05)$, with subjects more willing to trust institutional than interpersonal sources (data not shown). For these vendors, content remains not significant, and the interaction between source and content also is not significant. 


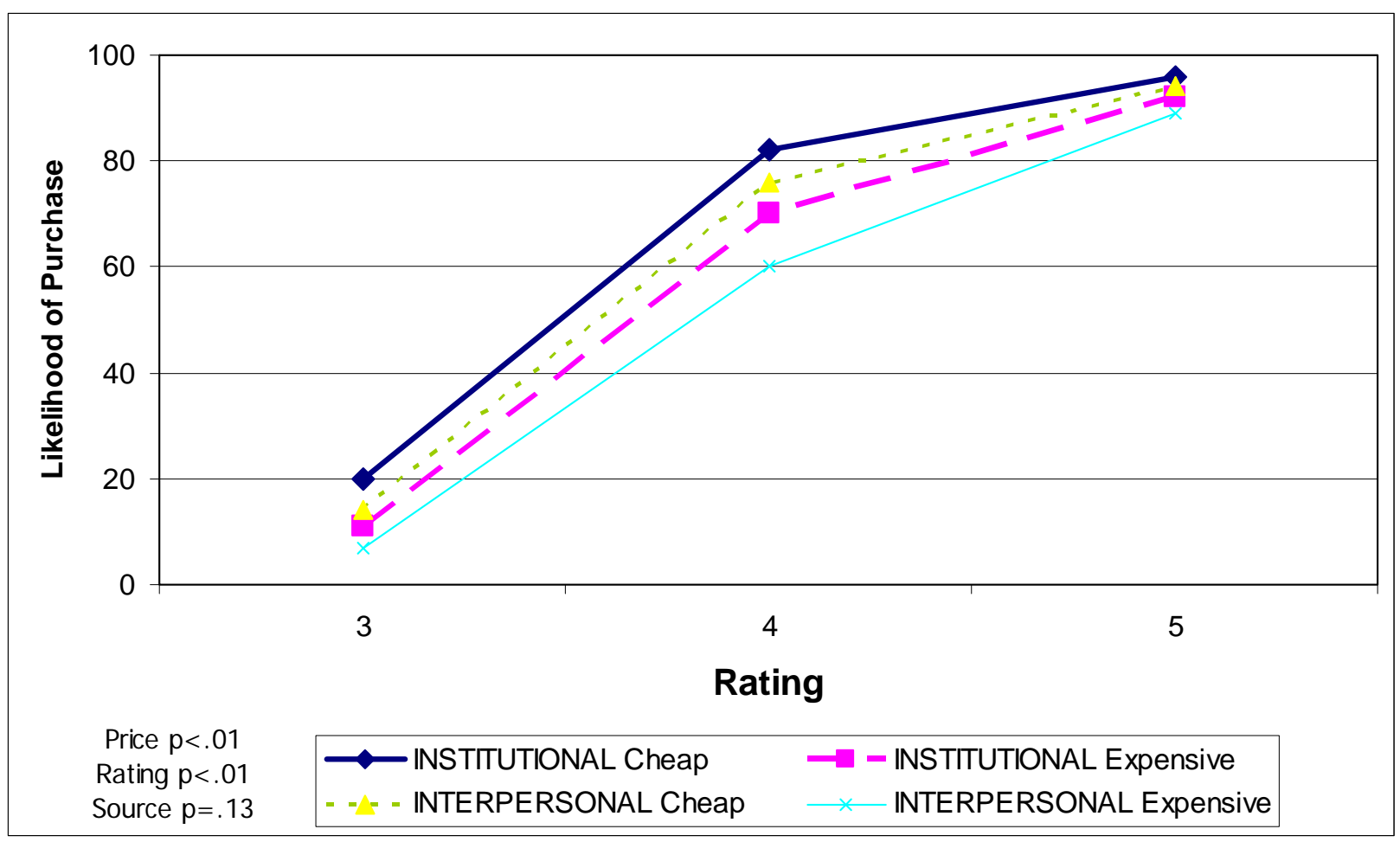

Figure 5. Likelihood of making an online purchase by price of good, vendor rating and source of information about vendor, $n=876$

In the full model for likelihood of purchase with rating, price, content and source, price $(p<.01)$, rating $(p<.10)$ and source $(p<.05)$ are significant, but content again is not nor is the interaction between source and content (data not shown).

These findings indicate that consumers appear to be somewhat more willing to make an online purchase when they have information about vendors from institutional third parties rather than feedback from other consumers especially when they have greater uncertainty about the vendor (e.g., vendors with a rating of 4). This finding is notable given the prevalence of peer reputation and recommender systems on the Internet. Subjects were very responsive to ratings of vendors regardless of the basis of the rating; the content of information consumers receive regarding vendors' security (reliability versus capability) had no effect on purchase decisions here. Perhaps subjects attended so strongly to the value of the rating that they paid little attention to the content.

\section{FUTURE RESEARCH DIRECTIONS}

We have presented suggestive findings that subjects appear more likely to trust when reputation information comes from an institutional source, but that they do not differentiate capability information from reliability information in choosing to trust a vendor. It may be the case that this experimental setting does not adequately capture the online marketplace or that our focus on transaction security may not apply to other trust problems that arise in online exchange. Whether these findings generalize to other domains of uncertainty in online exchange remains a question for future research. 
The very limited information regarding vendors provided in this experiment is not consistent with realworld websites. However, by designing and controlling an experimental online marketplace, we were able to investigate how specific forms and sources of information relevant to interpersonal and institutional trust influence consumers' willingness to make purchases from online vendors. Here we examined the simple question of whether subjects trusted in the vendor's legitimacy, controlling for price differences and holding constant the fair market value range as a proportion of the asking price. Future work may manipulate the fair market value range to represent uncertainty in product quality, such that some vendors offer items with much greater or lesser ambiguity in value. It also will allow subjects to bid what they would be willing to pay in the fair value range, giving a continuous measure of subjects' trust in the vendor.

This chapter has focused on the implications of uncertainty in Internet exchange but the advent of online exchange also increased vulnerability in transactions (the size of the potential loss). For example, to the extent that Internet infrastructure is not secure, such that aspects of the exchange are open to more than the two exchanging parties, entering a credit card number or bank account information may put one's account or identity at risk. Actors may be particularly concerned about losses to privacy because such damages are more difficult to quantify and therefore compensate. While important, the direct implications of increased vulnerability in Internet exchange are left to future work.

Future research may also consider differences in individual personality, including general attitudes toward trust (Simpson \& McGrimmon 2008) as well as variations across cultures (Cook et al, 2005; Kuwabara et $a l, 2007)$ in attitudes and behavior toward risk and uncertainty. These may affect how individuals respond to different types and sources of reputation information. Such questions may be addressed through straightforward extensions of the experiment presented here.

\section{CONCLUSION}

Trust plays an important role in economic exchange. As new technologies emerge for conducting exchanges online, established mechanisms of trust are disrupted or distorted because of increased uncertainty, which can lead to a breakdown of exchange. Despite the high levels of uncertainty among exchange partners on the Internet, prevalent online trust mechanisms appear to be based on a model of interpersonal rather than institutional trust. This is somewhat surprising given the crucial role served by institutional third parties in evaluating the reliability and capability of trading partners before the advent of online exchange. Further, the evidence shown here from an experimental online marketplace indicates that although consumers are responsive to reputation information from either interpersonal or institutional sources, they are more likely to trust in exchange with anonymous vendors when given reputation information from institutional third parties. This provides some preliminary evidence that creation and dissemination of institutional sources of information may facilitate online trust and commerce, but more importantly provides a number of specific directions for future research, which may elaborate and refine this goal. 


\section{REFERENCES}

Adler, M. (2009). History of NYC Sheet Music Store to Close. NPR

http://www.npr.org/templates/story/story.php?storyId=103728928

Akerlof, G. (1970). The market for lemons. The Quarterly Journal of Economics 84: 488-500.

Anthony, D.L. (2005). Cooperation in Micro-Credit Borrowing Groups: Identity, Sanctions and Reciprocity in the Production of Collective Goods. American Sociological Review 70(1): 496515.

\& Horne, C. (2003). Gender and Cooperation: Explaining loan repayment in micro-credit borrowing groups. Social Psychology Quarterly 66(3):293-302.

Axelrod, R. (1984). The Evolution of Cooperation. New York: Basic Books.

Ba, S., Whinston, A.B. \& Zhang, H. (2003) Building trust in online auction markets through an economic incentive mechanism. Decision Support Systems, 35( 3): 273-286.

Bacharach, M., \& Gambetta, D. (2001) Trust in Signs. In K.S. Cook (Ed.) Trust in Society (pp. 148-184). New York, NY: Russell Sage Foundation.

Barber, B. (1983). Logic and Limits of Trust. New Brunswick, NJ: Rutgers University Press.

Baye, M. (2002) Special Issue on The economics of the Internet and e-commerce. Advances in Applied Microeconomics. Volume 11.

Burt, R.S., \& Knez, M. (1996). Trust and Third-Party Gossip. In R.M. Kramer \& T.R. Tyler (Eds.) Trust in Organizations: Frontiers of Theory and Research (pp. 68-89). Thousand Oaks, CA: Sage.

Camp, L.J. (2000) Trust and Risk in Internet Commerce. The MIT Press, Cambridge, MA.

, Nissenbaum, H., \& McGrath, C. (2002). Trust: A collision of paradigms. Lecture Notes in Computer Science 2339:91-105.

Carruthers, B., Babb, S., \& Halliday, T. (2001). Institutionalizing Markets, or the Market for Institutions? Pp. 94-126 in The Rise of Neoliberalism and Institutionalism Analysis. John L. Campbell \& Ove K. Pedersen, editors. Princeton, NJ: Princeton University Press.

Cheshire, C., \& Cook, K.S. (2004). The Emergence of trust networks under uncertainty Implications for Internet interactions. Analyse \& Kritik 26: 220-240.

Cook, K.S., Rice, E.R., Gerbasi, A. (2004). The Emergence of Trust Networks under Uncertainty: The Case of Transitional Economies - Insights from Social Psychological Research. In S.R. Ackerman, B. Rothstein, J Kornai (Eds.), Problems of Post Socialist Transition: Creating Social Trust. New York, NY: 
Cook, K.S., Yamagishi, T., Cheshire, C., Cooper, R., Matsuda, M., \& Rie M. (2005). Trust Building via Risk Taking: A Cross-Societal Experiment. Social Psychology Quarterly 68: 121142.

Coleman, J. (1990). Foundations of Social Theory. Cambridge, MA: Belknap Press.

Datta, P., \& Chatterjee, S. (2008) The economics and psychology of consumer trust in intermediaries in electronic markets: the EM-Trust framework. European Journal of Information Systems 17:12-28.

David, S., \& Pinch, T. (2005). Six Degrees of Reputation: The Use and Abuse of Online Review and Recommendation Systems. Social Science Research Network Working Paper Series.

Dawes, R. (1980). Social Dilemmas. Annual Review of Psychology 31:169-93.

DiMaggio, P., \& Louch, H. (1998). Socially embedded consumer transactions: For what kinds of purchases do people most often use networks? American Sociological Review 63:619-637.

Falcone, R., Singh, M., Tan Y.H. (2001) Trust in Cyber-societies. Springer, Berlin.

Friedman, E., \& Resnick, P. (2001). The Social Costs of Cheap Pseudonyms. Journal of Economics and Management Strategy 10(2):173.

Froomkin, A.M. (1996) The essential role of trusted third parties in electronic commerce. In R. Kalakota, A.B. Whinston (Eds.), Readings in Electronic Commerce. Reading, Massachusetts: , Addison-Wesley.

Gambetta, D. (1988). Can We Trust Trust? In Diego Gambetta (Ed.) Trust Making and Breaking Cooperative Relations. New York: Basil Blackwell.

Garfinkle, H. (1967). Studies in Ethnomethodology. Englewood Cliffs, NJ: Prentice Hall.

Granovetter, M. (1985). Economic Action and Social Structure: The Problem of Embeddedness, American Journal of Sociology 91:481-510.

Greif, A. (1989). Reputation and Coalitions in medieval trade: Evidence on the Maghribi traders coalition. The Journal of Economic History 49: 857-882. . (1993). Contract enforceability and economic institutions in early trade: The Maghribi traders coalition. American Economic Review 83: 525-548.

Guseva, A., \& Rona-Tas, A. (2001). Uncertainty, Risk and Trust: Russian and American Credit Card Markets Compared, American Sociological Review 66 (5): 623-646.

Güth, W., \& Kliemt, H. (2004). The Evolution of Trust(worthiness) in the Net. Analyse \& Kritik 26: 203-219. 
Hardin, R. (2002). Trust and Trustworthiness. New York: Russell Sage.

Heimer, C.A. (2001). Solving the problem of trust. In K.S. Cook (Ed.) Trust in Society (pp. 4088). New York, NY: Russell Sage Foundation.

Kollock, P. (1994). The Emergence of Exchange Structures: An Experimental Study of Uncertainty, Commitment and Trust. American Journal of Sociology 100:313-345.

. (1999). The Production of trust in online markets. Advances in Group Processes 16:99-123.

, \& O’Brien, J. (1992). The Social Construction of Exchange. Advances in Group Processes

9: 89-112.

Kreps, D. (1990). Game Theory and Economic Modeling. New York: Oxford University Press.

Kuwabara, K., Willer, R., Macy, M.W., Mashima, R., Shigeru, T., \& Yamagishi, T. (2007). Culture, Identity, and Structure in Social Exchange: A Web-based Experiment in the United States and Japan. Social Psychology Quarterly 70: 461-479.

Luhmann, N. (1979). Trust and Power. Chichester: Wiley. . (1988). Familiarity, Confidence, Trust: Problems and Alternatives. Pp. 94-107 in Trust Making and Breaking Cooperative Relations. Edited by Diego Gambetta. New York: Basil Blackwell.

Lunn, R., \& Suman, M. (2002) Experience and Trust in Online Shopping. In: Wellman B, Haythornthwaite C (eds) The Internet in Everyday Life. Blackwell, Oxford UK.

Molm, L.D., Takahashi, N., \& Peterson, G. (2000). Risk and Trust in Social Exchange: An Experimental Test of a Classical Proposition. American Journal of Sociology, 105: 1396-427.

Perrow, C. (2002). Organizing America. Princeton, NJ: Princeton University Press.

Raub, W., \& Weesie, J. (1990). Reputation and Efficiency in Social Interactions: An Example of Network Effects. American Journal of Sociology 96:626-654.

Rasmusen, E. (1994). Games and Information. Second Edition. Cambridge, MA: Blackwell.

Resnick, P., Zeckhauser, R., Friedman, E., \& Kuwabara, K. (2000). Reputation systems: Facilitating trust in Internet interactions. Communications of ACM 43:45-48.

Schutz, A. (1970). On Phenomenology and Social Relations: Selected Writings. Chicago, IL: University of Chicago Press. 
Shapiro, S.P. (1987). The Social Control of Impersonal Trust. American Journal of Sociology 93:623-58.

Simon, H. (1955). A Behavioral Model of Rational Choice. Quarterly Journal of Economics 63:129-138.

Simpson, B., \& McGrimmon, T. (2008). Trust and Embedded Markets: A Multi-method Investigation of Consumer Transactions. Social Networks 30: 1-15.

Snijders, C. (1996). Trust and Commitments. Gronigen, Netherlands: Interuniversity Center for Social Science Theory and Methodology.

Yamagishi, T. (1995) Social Dilemmas. In K.S. Cook, G.A. Fine, J. House (Eds.), Sociological Perspectives on Social Psychology. Boston: Allyn \& Bacon.

, \& Yamagishi, M. (1994). Trust and Commitment in the United States and Japan. Motivation and Emotion 18:129-166.

, \& Matsuda, M. (2003). The Role of Reputation in Open and Closed Societies: An Experimental Study of Online Trading. Center for the Study of Cultural and Ecological Foundations of Mind, Working Paper Series 8. Retrieved May 1, 2009, from http://ynx.let.hokudai.ac.jp/COE21/english/workingpaper/index.html.

Ye, Z., Smith, S.W., \& Anthony, D. (2005). Trusted Paths for Browsers. ACM Journal Transactions on Information and System Security (TISSEC) 8(2):153-186.

Zucker, L.G. (1986). Production of Trust: Institutional Sources of Economic Structure, 1840-1920. Pp. 53-111 in Research in Organizational Behavior, volume 8. Edited by Barry M. Staw \& L.L. Cummings. Greenwich, CT: JAI Press Inc. 


\section{Endnotes}

1. Third party institutions also facilitate trust by limiting truster's vulnerability in exchange (see Heimer, 2001).

2. Of course some institutional third parties do exist to promote online exchange, such as certification authorities (CAs) like VeriSign, which authenticate the identity of trading parties in an online transaction (Ba et al, 2002; Froomkin, 1996). CAs play an important role in electronic commerce by authenticating actors (websites) and attesting to certain facts about them, making it somewhat more difficult for an online actor to change his identity. However, consumers do not necessarily understand the role or limits of CAs (Datta \& Chatterjee, 2008), nor are such entities resistant to corruption or abuse (Ye et al, 2005). 